\title{
Understanding how patient's personal value systems challenge nurses' views when providing care
}

\author{
Mary Jo Stanley* \\ School of Nursing, California State University Stanislaus, Turlock, California, United States
}

Received: February 11, 2018

DOI: $10.5430 /$ jnep.v8n9p68
Accepted: April 19, 2018

URL: https://doi.org/10.5430/jnep.v8n9p68

\begin{abstract}
Background: Personal conflict as a result of differences in value systems may be a moral challenge faced by nurses when caring for individuals with different cultures and beliefs than their own and is an area of limited study. As nurses care for patients with diverse backgrounds, it is inevitable that there may be differences in values and that these moral conflicts could be distressing. This type of moral distress can cause nurse's personal conflict as their values and beliefs may not match those of their patients. Methods: Moustakas (1994) phenomenological approach was used to elicit meaning from nurse's stories regarding morally challenging situations. Ten nurses were solicited, but only two wrote about their experiences; one worked in a busy emergency department and the other in a rural community setting.

Results: Four themes were identified: differences, moral code, weight of the transgression, and internal resolution. Value system conflict was the emergent constituent when nurses shared their stories of caring for patients with different values and beliefs than their own.

Conclusions: Nurses may be challenged to care for patients who have different cultural practices than themselves. Value system conflicts may cause strife for nurses who have different beliefs than the patients they care for. Interventions that support strategies to mitigate moral distress such as simulation could be included in future research. Use of simulation as a mechanism for training can assist nurses to work through morally challenging situations.
\end{abstract}

Key Words: Moral distress, Value system conflict, Moral challenges, Cultural diversity

\section{INTRODUCTION}

Nurses may be unprepared for the moral challenges they will encounter when caring for patients in the healthcare environment. While the concept of moral distress has been documented extensively in nursing ${ }^{[1-3]}$ there remains disagreement as to how moral distress is operationalized and conceptualized. ${ }^{[4,5]}$ Jameton's $^{[6]}$ definition of moral distress as a response to institutional constraints may not be sufficient to capture the personal experiences of nurses who feel conflicted or challenged. Hanna's ${ }^{[4]}$ definition offers another perspective and identifies moral distress as an "act of interior aversion which occurs with the perception of harm to an objective good." (p. 119). This definition suggests that there may be cultural considerations when we experience moral distress as the "objective good" may hold personal value for an individual. The many facets of moral distress necessitate the need to further explore and develop this concept as it pertains to nurses in healthcare. ${ }^{[3,5,7,8]}$

As nurses care for patients with diverse backgrounds, it is inevitable that there may be differences in values and that

\footnotetext{
*Correspondence: Mary Jo Stanley; Email: mstanley@csustan.edu; Address: School of Nursing, California State University Stanislaus, One University Ave, Turlock, CA. 95382, United States.
} 
these conflicting beliefs could have a distressing nature. ${ }^{[9,10]}$ The interpersonal aspect of the nurse and the patient places both parties in a relational situation where either could have differing practices. ${ }^{[11]} \mathrm{Hanna}^{[12]}$ suggests that moral distress can be experienced when personal beliefs or practices are compromised. Limited consideration has been given to personal moral values and the relational aspect this has to one's identity; a disruption of that moral relationship may cause resentment as core values become conflicted, compromised, or questioned. The area of conflicting values as influential in moral distress has had limited exploration within the literature and could provide further insight into nurses' moral conflict when caring for someone with differing value systems. ${ }^{[10]}$ This study seeks to understand nurse's experiences regarding moral challenges when caring for culturally diverse clients.

\section{Background}

Morally distressing situations can negatively affect nurses in clinical practice resulting in guilt, frustration, anger, and possibly influence the quality of the care provided. ${ }^{[13]}$ In addition, the consequence of holding onto unresolved moral distress has lasting effects evoking even stronger reactions to continued morally challenging situations. ${ }^{[14]}$ Moral distress is more than just an ethical dilemma, in fact, when faced with morally distressing situations where morals are compromised and one continues to carry the weight of those events, moral residue can take hold. ${ }^{[15,16]}$ Epstein and Delgado's ${ }^{[15]}$ case studies present conflicting situations for nurses where festering moral situations erode one's values over time affecting personal moral integrity. Hamric's ${ }^{[16]}$ case study analyzed the moral distress of a health care team caring for an infant in a neonatal intensive care unit highlighting the need for moral discourse in healthcare; to ignore the moral aspect of care can lead to a violation of personal values eroding one's core beliefs.

A combination of contributing factors such as personal views, cultural background, and external influences may contribute to an individual's moral distress and can influence one's personal moral values, and place someone at risk for moral distress. ${ }^{[17]}$ Studies involving end-of life have shown to evoke strong emotions from caregivers including subjective views that may conflict with the wishes of patients and their families. ${ }^{[9,18]}$ In fact, imposition of personal views about what is perceived as correct care can override those of the patient. ${ }^{[18]}$ A qualitative study with end-of-life elderly Jewish Orthodox patients explored conflicting values specific to cultural and religious differences that led to morally distressing experiences; nurses in the study experienced internal conflict when care was contrary to their beliefs. ${ }^{[9]}$ A mixed methods

Published by Sciedu Press design addressing ethical reasoning skills (a framework used to assess the morality of a situation) in students in a biotechnology program in secondary education found that one's own beliefs and attitudes can be influential in moral situations and may even override what is deemed morally correct. ${ }^{[10]}$ Personal conflict as a result of differences in value systems may be a moral challenge faced by nurses when caring for individuals with different values and beliefs than their own and is an area of limited study.

\section{Methodology}

A phenomenological qualitative design was chosen to further understand nurse's moral challenges in caring for patients with different cultural backgrounds. Participants from the western region of the United States were solicited through email flyers to local nursing colleges inviting faculty, RN-BSN and graduate students to participate in the study. Nurses who have passed the National Council Licensure Examination- Registered Nurse (NCLEX-RN) and worked a minimum of three months were invited to participate in the study. Ten participants completed consent forms, but only two participated in the study. Qualitative data was collected through interviews and written documentation of the participant's experiences (diaries); participants were asked to chronicle their experiences for three months describing any events or experiences that were perceived as morally challenging in caring for culturally diverse patients. No word limit was given to diary entries; participants typically wrote between 600-700 words for each described experience. In addition, semi-structured interviews were conducted; interviews lasted 30 minutes to one hour where participants clarified diary content, thereby, providing further checks for validity. The research study was Internal Review Board (IRB) approved through the university review process with all procedures in accordance with ethical standards; participants were provided with informed consent prior to data collection. Pseudonyms were used for participant identification.

Participants were both female, 51 and 52 years of age, Caucasian, with an average nursing experience of 20 years. One participant had experience with culturally diverse populations and worked in the emergency department (ED), the other participant worked with in a rural setting and had no experience with diverse populations prior to working at the health van (provides access to health services through a mobile vehicle). Both participants indicated having ethics classes as part of their education.

A phenomenological approach was employed to elicit participant perception of the experience where description provides understanding for the "meaning and essence of the experience" (P 58). ${ }^{[19]}$ Data were analyzed following Mous- 
takas $^{[19]}$ phenomenological approach: a) bracketing- the researcher's assumptions were set aside, the research process was focused on the question and topic; b) horizonalizationdiary entries and interview transcripts were reviewed with all content having equal weight. Participant's quotes provided insight into how the experience was perceived. Key statements and phrases were identified and coded. Analysis meeting with nursing research committee ensured consensus with identified coding; c) clustering the horizons into themes-significant statements were brought together to provide meaning. Four themes were identified and named based on the essence of the experiences; accord was obtained with the research chair; d) organizing the horizons and themes into a coherent textural description of the phenomena-the essence of the phenomena was extracted from the shared experiences of the participants; member checking with participants ensured agreement with researcher's interpretations. Rigor was achieved through engagement with the data, peer review, audit trail, member checking, and narrative diaries. ${ }^{[20]}$

\section{RESULTS}

Interpretation of findings from narrative diaries and interviews identified nurse's experiences regarding moral challenges when caring for patients with different cultural backgrounds. Four themes emerged: differences, moral code, weight of the transgression, and internal resolution.

\subsection{Differences}

Nurse participants identified cultural differences with their patients immediately upon the onset of the nurse-patient relationship. The nurses stated the physical and behavioral differences they identified that were contrary to their own when first exposed to the patient and situation.

Sandy's story. The patient looked a little rough. His body appeared to be one continuous tattoo. Most of these implied that he was a member of the Ku Klux Klan as well as a Hitler follower.

Ellen's story. Yesterday I encountered a patient that was in distress due to withdrawals from drugs. I had assumed this was initially due to his behavior, anxiety, and outward physical signs and it was confirmed when he had mentioned he was on Methadone.

\subsection{Moral code}

Participants both acknowledged a challenge to their personal moral code in response to the situation, yet felt an obligation to care for the patient. As care continued and the situation unfolded the nurses had a dutiful obligation, yet both struggled with their professional moral duty as well as their personal beliefs.
Sandy's story. I was at a loss for words and sick to my stomach. I had to continue to take care of the guy who stabbed his mother. I found myself angry with the punk who was now intubated and sedated... why did he deserve to live? I found myself going through the motions of keeping him alive despite what he had done. I don't like my emotions that I had with it... I morally wasn't supposed to feel that way.

Ellen's story. It was obvious that he was in turmoil and that he was experiencing heavy withdrawals... I would have thought to myself and may have stated to the patient that he just needs to get home and get off of the drugs. This experience was very unsettling to me.

\subsection{Weight of the transgression}

Participant's shared how the situations affected them with two different responses noted. The weight of the transgression as related to their value system may have had influence over their personal response to the situation.

Sandy's story. I believe murder is a grave sin. I found myself thinking that he didn't deserve to live. But who was I to judge?

Ellen's story. I tried to meet him where he was. I think many desire not to help this population because they feel that these patients choose to be drug abusers and therefore they don't deserve our help. And I feel very differently than that.

\subsection{Internal resolution}

Participant's struggled with internal resolution to the situations they encountered. Both nurses had strong emotional responses to the situations with two different reactions. Sandy was distraught after her experience with the patient stating the long term effect this had on her, personally. Ellen spoke of the morality of the situation, and the need to provide care to the patient.

Sandy's story. After the event, Ifound myself judging myselfas a nurse. I had spoken an oath. I was supposed to take care of anyone at any time NO MATTER WHAT! Yes, I took care of this killer, but it took everything I had to continue. It took several weeks for me to let my emotions go, and I spent several nights without sleep. I cried many tears over the death of the mother.

Ellen's story. For me, this disease no longer has a stigma attached to it. Addiction is no respector of persons. Just because a person is an addict does not mean they are morally deficient or any less of a human being. The patient deserves the same respect, help, and care as a patient with any other diagnosis. 


\section{Discussion}

Moustakas ${ }^{[19]}$ phenomenological approach was used to elicit meaning from nurse's stories regarding morally challenging situations when caring for patients with different cultural backgrounds; four themes emerged: differences, moral code, weight of the transgression, and internal resolution. Value system conflict was the emergent constituent when nurses shared their stories of caring for patients with different values and beliefs than their own. As shared by these nurses, conflicting values provoked real internal struggle and incongruity with their own beliefs. The nurses' personal value system is central to their own beliefs and identity, and opposition to this posed real strife for the nurses. Despite the participant's rich stories, a limitation of the study is the small sample size; input from only two nurses are included in this study.

Participants in the study cared for patients with different values and beliefs than their own as noted in the first theme differences, and instantly identified that they were in opposition with the practices of the patient they were caring for. Yap $^{[10]}$ makes a case for personal beliefs as influential in moral decision making and identified the need for an ethical framework in social-scientific education for students early on in their careers. Bressler, Hanna, and Smith's ${ }^{[9]}$ study showed nurses did experience internal conflict when providing care that was contrary to their values; nurses in their study asked for more education on cultural and religious issues to improve their ethical practice.

Similar to Bressler, Hanna, and Smith, ${ }^{[9]}$ the nurses in this study experienced internal conflict related to caring for patients with contrary beliefs and practices. As noted in the theme moral code, these differences challenged the nurse's values adding to their internal conflict and their moral obligation to care. Hamric ${ }^{[21]}$ discusses the destructive nature of moral distress as it can compromise the integrity of one's duty and core values. As seen in Sandy's response, she had extreme difficulty accepting the situation, stating it took her weeks to find resolution with the event. Sasso et al. ${ }^{[13]}$ identifies the need for a supportive process that takes into account one's cultural and religious characteristics. The ability to talk about and debrief regarding stressful situations is supported by research. ${ }^{[22]}$

The weight of the transgression produced different responses from the nurses. Sandy stated that the patient she cared for had committed a grave sin; this was in clear violation to her morals. In contrast, Ellen identified that some would not care for a drug user, but that she felt differently. These stories show two distinct differences in how the transgression was perceived; personal moral beliefs may influence how nurses

Published by Sciedu Press are affected by and react to culturally challenging situations. Repenshek ${ }^{[18]}$ discusses the moral subjectivity of end-of life care and the personal bias one might have in regards to patient care and decisions about care that may be in conflict with healthcare providers. Similar to research on moral imposition, mental health patients treated in the community felt care was imposed on them without consideration for their views on the treatment plan; critical reflection by healthcare providers on ethical practices and values was suggested to rectify these issues. ${ }^{[23]}$

The participant's perception regarding weight of the transgression could have been influential in how the nurses dealt with their own personal internal resolution. Sandy was distressed from the situation having both physical and emotion responses; she took weeks to feel she had found some level of resolve. Ellen felt her patient deserved care and dignity just like any other patient with a diagnosis. Similar to Hamric's ${ }^{[16]}$ study, Sandy may be experiencing moral residue related to the continual intensive ED environment in which she works. These unresolved feelings can threaten one's cores values. Hamric ${ }^{[16]}$ suggests conversations about ethical dimensions of care, collaboration with team members, and increased consultation for these morally challenging situations.

Discussion surrounding moral dimensions of care should take place in the healthcare environment. Providing nurses with training and instruction in the workplace and in schools of nursing to assist in dealing with difficult situations that cause internal conflict may reduce moral distress, yet limited intervention studies have been conducted to test suggestions offered in the literature. Further research using simulation or virtual simulated scenarios, as a mechanism to work through morally challenging situations has potential to provide moral training in a safe learning environment. Use of virtual patient cases or "interactive computer simulation of real-life clinical scenarios" (P 549) to teach ethics has been used with medical students in London. ${ }^{[24]}$ These scenarios resulted in improved decision-making skills and increased knowledge regarding ethics. Simulation has the potential to provide nurses and healthcare workers a training environment where communication, debriefing, consultation, exposure to cultural and religious issues, and collaboration can be practiced. Limited studies were found that included simulation as a primary intervention to assist nurses with moral challenges as a result of differing value systems when caring for patients who have beliefs and values different than their own.

\section{Conclusion}

Nurses are challenged to care for patients who have different cultural practices than themselves. Conflict in belief patterns 
may cause strife for nurses with different values and beliefs eliciting anger and resentment in one's work and in the patients they care for. Existing research has identified multiple facets of moral distress and the effects on job satisfaction, burnout, and quality of care. Yet, limited research has been done on differing value systems as influential toward moral distress. Use of simulation as a mechanism for training may assist nurses to work through morally challenging situations. Interventions that support strategies that mitigate moral distress must be included in future research.

\section{CONFLicts OF InTEREST Disclosure}

The author declares that there is no conflict of interest.

\section{REFERENCES}

[1] Brazil K, Kassalainen S, Ploeg J, et al. Moral distress experienced by health care professionals who provide home-based palliative care. Social Science \& Medicine. 2010; 71(9): 1687-1691. PMid:20832923 https://doi.org/10.1016/j.socscimed.2010.07.032

[2] Edwards M, McClement S, Read L. Nurses' responses to initial moral distress in long-term care. Journal of Bioethical Inquiry. 2013 10: 325-336. PMid:23793936 https : //doi .org/10.1007/s116 73-013-9463-6

[3] Peter E, Liaschenko J. Moral distress reexamined: A feminist interpretation of nurses' identities, relationships, and responsibilities. Journal of Bioethics Inquiry. 2013; 1(9): 338-342.

[4] Hanna DR. The lived experience of moral distress: Nurses who assisted with elective abortions. Research and Theory for Nursing Practice. 2005; 19: 95-124. https://doi.org/10.1891/rtnp.1 9.1.95.66335

[5] McCarthy J, Gastmans C. Moral distress: A review of the argumentbased nursing ethics literature. Nursing Ethics. 2015; 22(1): 131-152. PMid:25505098 https://doi .org/10.1177/09697330145571 39

[6] Jameton A. Nursing practice: The ethical issues. Upper Saddle River, NJ: Prentice Hall; 1984.

[7] McCarthy J, Deady R. Moral distress reconsidered. Nursing Ethics. 2008; 15(2): 254-262. PMid:18272615 https://doi.org/10.1 $177 / 0969733007086023$

[8] Pauly B, Varcoe C, Storch J. Framing the issues. HEC Forum. 2012; 24: 1-11. PMid:22446885 https://doi.org/10.1007/s10730 $-012-9176-y$

[9] Bressler T, Hanna D, Smith E. Making sense of moral distress within cultural complexity. Journal of Hospice \& Palliative Nursing. 2017; 19(1): 7-14. https://doi.org/10.1097/NJH.0000 000000000308

[10] Yap S. Beliefs, values, ethics and moral reasoning in socio-scientific education. Issues in Educational Research. 2014; 24(3): 299-319.

[11] Beckett A, Gilbertson S. Doing the right thing: Nursing students, relational practice, and moral agency. Journal of Nursing Education. 2007; 46(1): 28-32. PMid:17302097

[12] Hanna DR. Moral distress: the state of the science. Research Theory Nursing Practice. 2004; 18(1): 73-93. https ://doi .org/10.189 $1 / r \operatorname{tnp} .18 .1 .73 .28054$
[13] Sasso L, Bagnasco A, Bianchi M, et al. Moral distress in undergraduate nursing students: A systematic review. Nursing Ethics. 2016; 23(5): 523-534. PMid:25904547 https ://doi.org/10.1177/09 69733015574926

[14] Lamiani G, Borghi L, Argentero P. When healthcare professionals cannot do the right thing: A systematic review of moral distress and its correlates. Journal of Health Psychology. 2017; 22(1): 51-67. PMid:26220460 https ://doi.org/10.1177/13591053155951 20

[15] Epstein EG, Delgato S. Understanding and addressing moral distress. Online Journal of Issues in Nursing. 2010; 15(3).

[16] Hamric A. A case study of moral distress. Journal of Hospice \& Palliative Nursing. 2014; 16(8): 457-463. https ://doi.org/10.1 $097 /$ N JH. 0000000000000104

[17] Burston A, Tuckett A. Moral distress in nursing: Contributing factors, outcomes and interventions. Nursing Ethics. 2012; 20(3): 312-324. PMid:23275458

[18] Repenshek M. Moral distress: Inability to act or discomfort with moral subjectivity. Nursing Ethics. 2009; 16(6): 734-742. PMid:19889914 https://doi.org/10.1177/09697330093421 38

[19] Moustakas C. Phenomenological research methods. Thousand Oaks, CA: SAGE Publications; 1994.

[20] Lincoln YS, Guba EG. Naturalistic inquiry. Newbury Park, CA: SAGE Publications, Inc.; 1985.

[21] Hamric A. Empirical research on moral distress: Issues, challenges, and opportunities. HEC Forum. 2012; 24: 39-49. PMid:22476738 https ://doi.org/10.1007/s10730-012-9177-x

[22] De Veer A, Francke A, Struijs A, et al. Determinants of moral distress in daily nursing practice: A cross sectional correlational questionnaire survey. International Journal of Nursing Studies. 2013; 50: 100108. PMid:22989404 https://doi.org/10.1016/j.ijnurstu .2012 .08 .017

[23] Lawn S, Delany T, Pulvirenti M, et al. A qualitative study examining the presence and consequences of moral framings in patients' and mental health workers' experiences of community treatment orders. BMC Psychiatry. 2015; 15: 1-17.

[24] Hooper C. Ethics virtual patients: a new pedagogical tool for educators. Journal of Medical Ethics. 2015; 41: 549-552. PMid:25205388 https://doi.org/10.1136/medethics-2012-101154 